\title{
Modelo de competitividad para la industria textil y del vestido en México
}

\section{Model of Competitiveness for the Textile and Clothing Industry in Mexico}

\section{Modelo de competitividade para a industria têxtil e do vestuario no México}

\section{Jessica Nájera Ochoa}

Fecha de recibido: 15 de septiembre de 2014

Fecha de aprobado: 18 de diciembre de 2014

Doi: dx.doi.org/10.12804/rev.univ.empresa.28.2015.02

Para citar este artículo: Nájera O., J. (2015). Modelo de competitividad para la industria textil del vestido en México. Universidad \& Empresa, 17(28), 37-68. Doi: dx.doi.org/10.12804/rev.univ.empresa.28.2015.02

\section{RESUMEN}

Esta investigación se realizó en empresas de la industria textil y del vestido en México. El objetivo del trabajo es determinar en qué medida los factores de productividad, calidad e innovación, enfocados en los recursos y las capacidades de la empresa, inciden en la competitividad de esta industria. El estudio efectuado, como resultado principal, permite contar con los elementos necesarios para diseñar un modelo de competitividad útil al desarrollo de estrategias que generen ventajas competitivas para esta.

Palabras clave: competitividad, estrategia, industria de la confección y del vestido en México, industria textil mexicana, sector textil mexicano.

Doctorado en Ciencias Administrativas en el Instituto Politécnico Nacional (Distrito Federal, México). Docente Investigadora, Escuela Superior de Comercio y Administración, Unidad Santo Tomás (Distrito Federal, México). Correo electrónico: jnajerao@yahoo.com.mx. Dirección postal: Escuela Superior de Comercio y Administración, Unidad Santo Tomás, Avenida Manuel Carpio 471, Colonia Plutarco Elías Calles, Código Postal 11340 (Distrito Federal, México). 


\section{ABSTRACT}

This research was carried out in textile and clothing industry companies in Mexico. The purpose of the work is to determine to what extent the productivity, quality and innovation factors, focused on the resources and capabilities of the enterprise, influence the competitiveness of this industry. The main result of the study provides the elements necessary to design a model of competitiveness useful for the development of strategies that create competitive advantages for it.

Keywords: Competitiveness, clothing industry in Mexico, Mexican textile industry, Mexican textile sector, strategy.

\section{RESUMO}

Esta pesquisa se realizou em empresas da indústria têxtil e do vestido no México. O objetivo do trabalho é determinar em que medida os fatores de produtividade, qualidade e inovação, focados nos recursos e nas capacidades da empresa, incidem na competitividade desta indústria. O estudo efetuado, como resultado principal, permite contar com os elementos necessários para desenhar um modelo de competitividade útil ao desenvolvimento de estratégias que gerem vantagens competitivas para esta.

Palavras-chave: competitividade, estratégia, indústria da confecção e do vestido no México, indústria têxtil mexicana, setor têxtil mexicano. 


\section{INTRODUCCIÓN}

Esta investigación se enfoca en el análisis del estado actual de la industria textil y del vestido en México. Esta es estudiada dentro de un contexto de globalización y es observada a partir de la relevancia que pueden tener los factores de productividad, calidad e innovación - considerando los recursos y las capacidades de la empresa - para el desarrollo de un modelo que permita mejorar su competitividad.

A partir de los datos respecto al comportamiento del mercado mundial de textiles y prendas de vestir(Organización Mundial del Comercio [OMC], 2013), así como de los indicadores económicos clave de la industria textil y de la confección en México (Secretaria de Economía, 2014a, 2014b) puede observarse una marcada y constante pérdida de competitividad desde hace más de una década.

En 2000, México era el cuarto exportador mundial de prendas de vestir y cubría el $4 \%$ del mercado mundial. En ese mismo año, China, que ya era el primer exportador global, abastecía el $18 \%$ de ese mercado. Doce años después, la participación de México cayó al 1\%, llegando a ocupar el decimoséptimo lugar en 2012. En ese mismo año, en cambio, China satisfacía ya el $38 \%$ de las exportaciones globales de textiles (OMC, 2013).

En la actualidad, México es superado en exportaciones mundiales de textiles por países con menor tamaño de mercado como Bangladesh, Turquía, Indonesia y Malasia. De hecho, tomando en cuenta su tendencia de crecimiento, este podría llegar a ser superado dentro de pocos años por naciones como Camboya, Tailandia, Pakistán y Sri Lanka (OMC, 2013).

Los indicadores clave de la industria textil (suministros para la confección), incorporados en la tabla 1; así como los de la industria de la confección (productos textiles terminados que incluyen prendas de vestir), presentados en la tabla 2, muestran una tendencia negativa para el periodo 2007-2012: 
Tabla 1. Indicadores clave de la industria textil ${ }^{0}$

\begin{tabular}{|c|c|c|c|c|c|c|c|c|}
\hline Indicador & Unidades & 2007 & 2008 & 2009 & 2010 & 2011 & 2012 & Crecimiento \\
\hline Producción ${ }^{1}$ & $\begin{array}{l}\text { Millones } \\
\text { de pesos }\end{array}$ & 17.876 & 16.624 & 15.400 & 17.085 & 16.321 & 16.828 & -1.048 \\
\hline $\begin{array}{l}\% \text { Crecimiento } \\
\text { anual }\end{array}$ & Porcentaje & $-3,37 \%$ & $-7,00 \%$ & $-7,36 \%$ & $10,94 \%$ & $-4,47 \%$ & $3,11 \%$ & $-8,78 \%$ \\
\hline$\%$ PIB Total & Porcentaje & $0,15 \%$ & $0,14 \%$ & $0,13 \%$ & $0,14 \%$ & $0,13 \%$ & $0,13 \%$ & $0,82 \%$ \\
\hline $\begin{array}{l}\% \text { PIB } \\
\text { Manufactura }\end{array}$ & Porcentaje & $0,87 \%$ & $0,82 \%$ & $0,83 \%$ & $0,85 \%$ & $0,77 \%$ & $0,77 \%$ & $4,94 \%$ \\
\hline $\begin{array}{l}\text { Balanza } \\
\text { Comercial }\end{array}$ & $\begin{array}{l}\text { Millones } \\
\text { de dólares }\end{array}$ & -4.543 & -4.450 & -3.398 & -4.318 & -5.007 & -4.597 & -54 \\
\hline Exportaciones $^{2}$ & $\begin{array}{l}\text { Millones } \\
\text { de dólares }\end{array}$ & 1.487 & 1.347 & 998 & 1.286 & 1.522 & 1.621 & 134 \\
\hline Importaciones $^{2}$ & $\begin{array}{l}\text { Millones } \\
\text { de dólares }\end{array}$ & 6.030 & 5.797 & 4.397 & 5.604 & 6.529 & 6.218 & 188 \\
\hline $\begin{array}{l}\% \text { Exportaciones } \\
\text { Total }\end{array}$ & Porcentaje & $0,55 \%$ & $0,46 \%$ & $0,43 \%$ & $0,43 \%$ & $0,44 \%$ & $0,44 \%$ & $2,76 \%$ \\
\hline $\begin{array}{l}\text { \% Exportaciones } \\
\text { Manufactura }\end{array}$ & Porcentaje & $0,68 \%$ & $0,58 \%$ & $0,53 \%$ & $0,52 \%$ & $0,55 \%$ & $0,54 \%$ & $3,42 \%$ \\
\hline Empleo $^{3}$ & Empleados & 72.209 & 66.294 & 60.419 & 60.050 & 59.228 & 58.266 & -13.943 \\
\hline $\begin{array}{l}\% \text { Empleo } \\
\text { Manufactura }\end{array}$ & Porcentaje & $2,20 \%$ & $2,04 \%$ & $2,04 \%$ & $1,96 \%$ & $1,87 \%$ & $1,80 \%$ & $12,11 \%$ \\
\hline No Empresas ${ }^{3}$ & Unidades & 314 & 302 & 290 & 263 & 258 & 249 & -65 \\
\hline $\begin{array}{l}\text { Ventas } \\
\text { nacionales }^{3}\end{array}$ & $\begin{array}{l}\text { Millones } \\
\text { de pesos }\end{array}$ & 35.350 & 34.472 & 36.272 & 41.073 & 45.124 & 45.893 & 10.543 \\
\hline $\begin{array}{l}\text { Inversión } \\
\text { extranjera } \\
\text { directa }^{4}\end{array}$ & $\begin{array}{l}\text { Millones } \\
\text { de dólares }\end{array}$ & $-13,61$ & 71,07 & 12,24 & 44,51 & $-1,71$ & 10,1 & 123 \\
\hline \multicolumn{9}{|c|}{$\begin{array}{ll}0 & \text { La industria textil comprende la fabricación de insumos textiles y acabado de textiles, Secretaría de Economía. } \\
1 & \text { PIB a precios de 2008. Sistema de Cuentas Nacionales, INEGI. } \\
2 & \text { Grupo de Trabajo de Estadísticas de Comercio Exterior, Banco de México, INEGI, SAT y la Secretaría de Economía. } \\
3 & \text { Encuesta Mensual y Anual de la Industria Manufacturera, INEGI. } \\
4 & \text { Secretaría de Economía. }\end{array}$} \\
\hline
\end{tabular}

Fuente: elaboración propia, a partir de datos de la Secretaría de Economía (2014a, p. 1). 
Tabla 2. Indicadores clave de la industria de la confección ${ }^{0}$

\begin{tabular}{|c|c|c|c|c|c|c|c|c|}
\hline Indicador & Unidades & 2007 & 2008 & 2009 & 2010 & 2011 & 2012 & Crecimiento \\
\hline Producción ${ }^{1}$ & $\begin{array}{l}\text { Millones } \\
\text { de pesos }\end{array}$ & 69.116 & 68.870 & 63.604 & 66.276 & 65.993 & 65.562 & -3.554 \\
\hline $\begin{array}{l}\% \text { Crecimiento } \\
\text { anual }\end{array}$ & Por ciento & $-3,08 \%$ & $-0,36 \%$ & $-7,65 \%$ & $4,20 \%$ & $-0,43 \%$ & $-0,65 \%$ & $-8,27 \%$ \\
\hline$\%$ PIB Total & Por ciento & $0,57 \%$ & $0,56 \%$ & $0,54 \%$ & $0,54 \%$ & $0,52 \%$ & $0,49 \%$ & $3,23 \%$ \\
\hline $\begin{array}{l}\% \text { PIB } \\
\text { Manufactura }\end{array}$ & Por ciento & $3,37 \%$ & $3,40 \%$ & $3,42 \%$ & $3,29 \%$ & $3,13 \%$ & $3,00 \%$ & $20,16 \%$ \\
\hline $\begin{array}{l}\text { Balanza } \\
\text { Comercial }\end{array}$ & $\begin{array}{l}\text { Millones } \\
\text { de dólares }\end{array}$ & 3.183 & 2.799 & 2.344 & 2.494 & 2.348 & 1.914 & -1.269 \\
\hline Exportaciones $^{2}$ & $\begin{array}{l}\text { Millones } \\
\text { de dólares }\end{array}$ & 5.831 & 5.515 & 4.666 & 4.980 & 5.321 & 5.122 & -709 \\
\hline Importaciones $^{2}$ & $\begin{array}{l}\text { Millones } \\
\text { de dólares }\end{array}$ & 2.648 & 2.716 & 2.322 & 2.486 & 2.973 & 3.207 & 559 \\
\hline $\begin{array}{l}\% \text { Exportaciones } \\
\text { Total }\end{array}$ & Por ciento & $2,14 \%$ & $1,89 \%$ & $2,03 \%$ & $1,67 \%$ & $1,52 \%$ & $1,38 \%$ & $10,79 \%$ \\
\hline $\begin{array}{l}\text { \% Exportaciones } \\
\text { Manufactura }\end{array}$ & Por ciento & $2,65 \%$ & $2,39 \%$ & $2,46 \%$ & $2,03 \%$ & $1,91 \%$ & $1,70 \%$ & $13,39 \%$ \\
\hline Empleo $^{3}$ & Empleados & 220.537 & 207.389 & 188.098 & 178.942 & 170.637 & 166.694 & -53.843 \\
\hline $\begin{array}{l}\% \text { Empleo } \\
\text { Manufactura }\end{array}$ & Por ciento & $6,70 \%$ & $6,38 \%$ & $6,34 \%$ & $5,83 \%$ & $5,40 \%$ & $5,16 \%$ & $37,70 \%$ \\
\hline No Empresas ${ }^{3}$ & Unidades & 1.155 & 1.180 & 1.124 & 1.027 & 988 & 910 & -245 \\
\hline $\begin{array}{l}\text { Ventas } \\
\text { nacionales }^{3}\end{array}$ & $\begin{array}{l}\text { Millones } \\
\text { de pesos }\end{array}$ & 40.478 & 40.367 & 39.758 & 41.364 & 44.324 & 46.344 & 5.866 \\
\hline $\begin{array}{l}\text { Inversión } \\
\text { extranjera } \\
\text { directa }^{4}\end{array}$ & $\begin{array}{l}\text { Millones } \\
\text { de dólares }\end{array}$ & 263 & 254 & 315 & 262 & 103 & 151 & -112 \\
\hline \multicolumn{9}{|c|}{$\begin{array}{ll}0 & \text { La industria de la confección comprende la fabricación de todo tipo de productos textiles acabados, incluidas prendas } \\
& \text { de vestir, SE. } \\
1 & \text { PIB a precios de 2008. Sistema de Cuentas Nacionales, INEGI. } \\
2 & \text { Grupo de Trabajo de Estadísticas de Comercio Exterior, Banco de México, INEGI, SAT y la Secretaría de Economía } \\
3 & \text { Encuesta Mensual y Anual de la Industria Manufacturera, INEGI. } \\
4 & \text { Secretaría de Economía. }\end{array}$} \\
\hline
\end{tabular}

Fuente: elaboración propia, a partir de datos de la Secretaría de Economía (2014b, p. 1). 
En esta industria, como se observa, la producción, el aporte al Producto Interno Bruto (PIB) total y al PIB del sector manufactura, el empleo, la participación en el total del sector manufactura, el número de empresas y la Inversión Extranjera Directa (IED) han disminuido de forma constante y marcada durante el periodo indicado. Las ventas nacionales disminuyeron un $23 \%$ mientras que la balanza comercial es deficitaria en una proporción de 3 a 1 . Se ha perdido el $32 \%$ de puestos de trabajo, el número de empresas ha disminuido un $21 \%$ mientras que la IED ha sido muy volátil durante todo el periodo, siendo en 2012 un 57\% menor que en 2007 (Secretaría de Economía, 2014).

\section{MARCO TEÓRICO}

A continuación, se presenta el resultado de un ejercicio de revisión de literatura alrededor de conceptos y planteamientos teóricos esenciales para la configuración del modelo que resulta de este trabajo:

\subsection{Estrategia competitiva}

\subsubsection{Ventaja competitiva}

Las empresas enfrentan cambios rápidos y constantes en su entorno. Deben adaptarse a estos por medio de la identificación y el desarrollo de ventajas competitivas, diferenciales, sostenibles y defendibles a largo plazo (Porter, 1989). Esto es necesario no solo para ingresar al mercado, sino también para asegurar su sobrevivencia e incrementar paulatinamente su rentabilidad y el crecimiento (Comisión Presidencial para la Competitividad Industrial [CPCI], 1991; Müller, 1995; Pérez, 1996; Tamames, 1988).

Las empresas pueden desarrollar ventajas competitivas, entre otras alternativas, a través de 1) una determinada organización de sus recursos humanos y materiales (Díaz, 2003), 2) costos de producción inferiores, productos diferenciados o focalización (Porter, 1989) y 3) estrategias competitivas específicas desarrolladas, por ejemplo, con base en un análisis interno (de las fortalezas y debilidades de la compañía) y externo (de las oportunidades y amenazas existentes en el entorno) (David, 2011). Por otro lado, estas también pueden estudiar su cadena de valor con el fin de identificar y evaluar cada una de sus actividades. Esto en función de la reducción de gastos o la aportación de diferenciación en la creación de valor (Porter, 1982).

Es importante ofrecer valor agregado a los clientes en la forma de precios más bajos que los competidores, ya sea esto por beneficios equiva- 
lentes o por proporcionar provechos únicos que, eventualmente, lleguen a justificar incluso la presencia de un precio mayor (Porter, 1989). Para hacer esto es necesario conocer en cuanto sea posible las necesidades de los consumidores, así como sus gustos, deseos y comportamientos, y disponer de los recursos técnicos, comerciales y económicos necesarios (Díaz, 2003).

Porter $(1982,1989,1990)$ destaca, entre las acciones clave para la obtención de ventaja competitiva, las siguientes:

- Desarrollar estrategias de obtención de costos inferiores o productos diferenciados.

- Establecer procesos de producción más eficientes para el incremento de la productividad y la reducción de precios para los clientes.

- Ofrecer productos y servicios de calidad superior.

- Identificar y valorar las actividades desarrolladas para diseñar, producir, comercializar, entregar y dar soporte a los productos de la empresa para la mejora de los procesos.

- Desarrollar productos más avanzados tecnológicamente iguales - con precios más bajos que los de la competencia e identificar, investigar y desarrollar productos nuevos en forma veloz, con gran calidad y a un costo razonable.

- Proporcionar servicios de valor agregado y mejorar el servicio de soporte al cliente, con enfoque en la solución de sus problemas.

- Mejorar los procedimientos de recepción y aprobación de pedidos, el envío de productos y la gestión de la cobranza.

- Combinar mediante una estrategia adecuada los recursos productivos, las aptitudes del personal y las oportunidades del medio. Empleando para esto los recursos de la empresa, de manera óptima, para el crecimiento y la rentabilidad.

- Administrar los niveles adecuados de inventarios de materias primas, así como de productos semiterminados y terminados. Esto de manera que existan suficientes suministros disponibles, mientras se evitan los costos de almacenaje asociados al exceso de existencias.

- Obtener condiciones favorables de los proveedores en precio y tamaño de pedidos de insumos, garantizando el abastecimiento de aquellos que sean clave para la empresa y disponiendo de proveedores de materias primas sustitutas. 
Otras acciones clave para la obtención de ventaja competitiva son:

- Explotar los recursos y capacidades internas y únicas de la organización, poniendo una especial atención a la importancia de la innovación y el papel central de los procesos al interior de la empresa (Suárez \& Ibarra, 2004).

- Estudiar la cadena de valor de la compañía para conocer cómo cada una de sus actividades influye o no a la creación del valor para el cliente (Díaz, 2003).

- Administrar eficientemente las diversas funciones de la empresa: producción, mercadotecnia, finanzas, investigación y desarrollo, recursos humanos, etc. (Stoner, Freeman, \& Gilbert, 1996).

- Estimular una actitud centrada en el aprendizaje tecnológico, con la que se garanticen la innovación y la adaptación tecnológica (Díaz, 2003).

- Promover el aprendizaje tecnológico, garantizando así la innovación y la adaptación tecnológica (Díaz, 2003).

- Reconocer la importancia de la innovación y el papel central de los procesos internos en la empresa (Suárez \& Ibarra, 2004).

- Cuidar la reputación en las relaciones con el cliente, la calidad de los productos, los vínculos con proveedores y otros entes, así como las marcas, patentes y la propiedad intelectual en las que se apoya la protección legal del conocimiento de la empresa (Barney \& Arikan, 2001; Grant, 1996).

- Consolidar la tecnología o aumentar la calidad de los productos y servicios en relación con aquellos ofrecidos por los competidores (Barney, 1991).

- Motivar la participación, la creatividad, la innovación continua y el emprendimiento corporativo (Burns \& Stalker, 1961; Harrison, 1987; Rialp, 2003).

\subsubsection{Competitividad}

La competitividad puede entenderse como la capacidad que tienen las empresas para captar mercados e incrementar de forma sostenida sus ventas y rentabilidad (Cho, 1994; CPCI, 1991; Pérez, 1996; Porter, 1991; Tamames, 1988; Tyson, 1992; Vallejo, 2003). Las compañías se ven enfrentadas a desarrollarla, en particular, cuando se encuentran en un ambiente en el que necesitan competir para mantenerse y desarrollarse (Comisión Económica para América Latina y el Caribe [CEPAL], 2003; CPCI, 1991; Guerrero, 1995; Müller, 1995; Pérez, 1996; Porter, 1991; Tamames, 1988). 
La competitividad puede considerarse, en lo fundamental, en tres niveles:

1. Empresa (Abd-el-Rahman, 1995; Alic, 1987; Alonso, 1992; Barney \& Griffin, 1992; CEPAL, 2003; Chesnais, 1986; Cho, 1994; Díaz, 2003; Feenstra, 1998; Francis, 1989; Guerrero, 1995; Michalet, 1981; Morales \& Pech, 2003; Mü1ler, 1995; OCDE, 2000; Porter, 1991; Sallenave, 1995; Tavares, Haguenauer, \& Bosco, 1990).

2. Industria (Abd-el-Rahman, 1995; Alonso, 1992; CEPAL, 2003; Chesnais, 1986; Cho, 1994;Díaz, 2003; Feenstra, 1998; Guerrero, 1995; Müller, 1995; Porter, 1991; OCDE, 2000; Tavares, Haguenauer, \& Bosco, 1990).

3. País (CEPAL, 2003; Chesnais, 1986; Cho, 1994; Coriat, 1997; Díaz,2003; Fagerberg, 1998; Fajnzylber, 1988; Feenstra, 1998; Guerrero, 1995; Instituto Mexicano para la Competitividad [IMCO], 2010; International Institute for Management Development [IMD], 2013; Moon, Rugman, \& Verbeke, 1995; Morales \& Pech, 2003; Müller, 1995; Organización para la Cooperación y el Desarrollo Económicos [OCDE], 2000; Porter, 1991; Tyson, 1992; World Economic Forum [WEF], 2013).
A nivel de la empresa y la industria, la competitividad se reconoce por el crecimiento de la compañía - o por el número de estas, según sea el caso-, su tamaño, cuota de mercado nacional e internacional y la cantidad de empleados con la que se cuenta, así como por el incremento de la producción, las ventas, la rentabilidad y el valor de la(s) organización(es) y sus productos (CEPAL, 2003; Feenstra, 1998; Porter, 1991; Tamames, 1988; OCDE, 2000; Chesnais, 2001; Esser, Hillebrand, Messner, \& Meyer-Stamer, 1994; Sallenave, 1995; Vallejo, 2003; Cho, 1994). A nivel del país, esta se mide principalmente por el aumento positivo de la balanza comercial y el incremento de la participación en el mercado externo e interno (Abd-el-Rahman, 1995; Alic, 1987; Alonso, 1992; Coriat, 1997; CPCI, 1991; Esser, Hillebrand, Messner, \& Meyer Stamer, 1994; Fajnzylber, 1988; Feenstra, 1998; Francis, 1989; Müller, 1995; OCDE, 2000; Pérez, 1996; Tamames, 1988; WEF, 2013).

La competitividad, en cualquiera de sus tres niveles (empresa, industria o país), puede obtenerse principalmente a través del enfoque en tres factores clave. Estos son:

1. La productividad (Abd-el-Rahman, 1995; CEPAL, 2003; Coriat, 
1997; Díaz, 2003; Esser, Hillebrand, Messner, \& MeyerStamer, 1994; Fajnzylber, 1988; OCDE, 2000; Porter, 1991; Tavares, Haguenauer, \& Bosco, 1990; WEF, 2013).

2. La calidad (Alonso, 1992; Díaz, 2003; Esser,Hillebrand, Messner, \& Meyer Stamer, 1994; Fagerberg, 1998; Pérez, 1996; Tavares, Haguenauer, \& Bosco, 1990; Va1lejo, 2003; WEF, 2013).

3. La innovación (Chesnais, 1986; Coriat, 1997; CPCI, 1991; Díaz, 2003; Esser, Hillebrand, Messner, \& Meyer Stamer, 1994; Porter, 1991; WEF, 2013).

Estos factores deben ser aplicados a los recursos y las capacidades de la empresa (Barney \& Griffin, 1992; Chesnais, 1986; Cho, 1994; Guerrero, 1995; Müller, 1995 Porter, 1991; WEF, 2013). El hecho de que un país cuente con empresas e industrias competitivas puede promover el desarrollo económico, incrementar el nivel de ingreso y el empleo, proporcionar mayor bienestar a la población y aumentar su calidad de vida
(CEPAL, 2003; Coriat, 1997; Esser, Hillebrand, Messner, \& Meyer Stamer, 1994; Fagerberg, 1998; Fajnzylber, 1988; OCDE, 2000; WEF, 1996, 2013).

\subsection{Teoría de los recursos y las capacidades}

Entre los últimos años de la década del ochenta y los inicios del noventa, el centro de interés del análisis de la ventaja competitiva se desplazó rápidamente del estudio de la relación entre estrategia y entorno hacia el análisis de los aspectos internos de la empresa. Esto, en particular, con un énfasis en la explotación de los recursos y las capacidades internas únicas de la organización para la obtención de dicha ventaja competitiva (Suárez \& Ibarra, 2004). Los recursos (activos) de la empresa se agrupan en dos categorías: 1) tangibles y 2) intangibles (Barney \& Arikan, 2001; Barney, 1991; Cardona, 2011; Galbraith, 2005; Grant, 1991; Grant, 1996; Hall, 1992; Weston \& Brigham, 1994; Wernerfelt, 1984). Estos se muestran en la tabla 3. 
Tabla 3. Los recursos de la empresa

\begin{tabular}{|c|c|}
\hline \multicolumn{2}{|r|}{ Recursos de la empresa } \\
\hline \multicolumn{2}{|r|}{ Recursos tangibles } \\
\hline Recursos físicos (materiales) & Recursos financieros \\
\hline $\begin{array}{l}\text { Edificios. } \\
\text { Instalaciones. } \\
\text { Equipo y maquinaria. } \\
\text { Inventario de materia prima. } \\
\text { Inventario de productos. } \\
\text { Localización geográfica. } \\
\text { Acceso a materia prima. } \\
\text { Integración en clústeres. }\end{array}$ & $\begin{array}{l}\text { Fondos. } \\
\text { Créditos. } \\
\text { Seguros. } \\
\text { Cuentas por cobrar. }\end{array}$ \\
\hline \multicolumn{2}{|r|}{ Recursos intangibles } \\
\hline Activos intelectuales & $\begin{array}{l}\text { Recursos de capital humano (recursos humanos), habilidades } \\
\text { (competencias o capacidades) del personal }\end{array}$ \\
\hline $\begin{array}{l}\text { Nombres de marca. } \\
\text { Patentes. } \\
\text { Copyright. } \\
\text { Diseños industriales. } \\
\text { Tecnología propia. } \\
\text { Procesos. }\end{array}$ & \multirow{4}{*}{$\begin{array}{l}\text { Preparación. } \\
\text { Experiencia. } \\
\text { Capacitación. } \\
\text { Potencial de aprendizaje. } \\
\text { Apertura al cambio. } \\
\text { Capacidad de adaptación. } \\
\text { Habilidad de trabajo en equipo. } \\
\text { Relaciones personales. } \\
\text { Liderazgo. } \\
\text { Capacidad de toma de decisiones. } \\
\text { Motivación. } \\
\text { Creatividad. } \\
\text { Emprendimiento. } \\
\text { Aspectos sicológicos. } \\
\text { Aspectos sociológicos. }\end{array}$} \\
\hline Activos comerciales & \\
\hline $\begin{array}{l}\text { Licencias de uso. } \\
\text { Concesiones. } \\
\text { Secretos comerciales. } \\
\text { Bases de datos. } \\
\text { Contactos comerciales. } \\
\text { Cartera de clientes. }\end{array}$ & \\
\hline Reputación & \\
\hline $\begin{array}{l}\text { Reputación de la empresa. } \\
\text { Reputación de las marcas. } \\
\text { Reputación de los productos. }\end{array}$ & \multirow[t]{2}{*}{$\begin{array}{l}\text { Recursos de capital organizacional (activos organizativos), } \\
\text { habilidades (competencias o capacidades) organizativas }\end{array}$} \\
\hline Cultura organizacional & \\
\hline $\begin{array}{l}\text { Valores. } \\
\text { Tradiciones. } \\
\text { Normas sociales. }\end{array}$ & $\begin{array}{l}\text { Estructura organizacional. } \\
\text { Procesos organizacionales. } \\
\text { Líneas de autoridad. } \\
\text { Forma de reportes. } \\
\text { Planeación formal e informal. } \\
\text { Control. } \\
\text { Coordinación de sistemas. } \\
\text { Relaciones con los proveedores. } \\
\text { Relaciones con los distribuidores. }\end{array}$ \\
\hline
\end{tabular}

Fuente: elaboración propia, a partir de Barney (1991), Barney y Arikan (2001), Cardona (2011), Galbraith (2005), Grant (1991, 1996), Hall (1992), Wernerfelt (1984) y Weston y Brigham (1994). 


\subsubsection{Los recursos de la empresa}

Para Wernerfelt (1984) deben considerarse como recursos de la empresa todos aquellos activos tangibles e intangibles que se vinculen a esta de forma semipermanente. Esto ocurre, por ejemplo, el caso de marcas, conocimiento tecnológico propio, personal calificado, contactos comerciales, maquinaria y procedimientos eficientes y de capital. Se considera esto con independencia de que estos aspectos sean percibidos como fortalezas o como debilidades de la organización. Barney (1991) considera que los recursos de una empresa son "los activos, capacidades, procesos organizacionales, información, conocimientos, etc., que son controlados por la empresa y que le permiten concebir y poner en marcha sus estrategias" (p. 101).

De acuerdo con Hall (1992), los recursos materiales o tangibles comprenden tanto los físicos (edificios, instalaciones, equipo y maquinaria, inventarios de materias primas y productos, etc.), como los financieros (fondos, seguros, cuentas por cobrar), etc., mientras que los intangibles se agrupan en activos y habilidades.

Los recursos intangibles catalogados como activos incluyen patentes, nombres de marca, copyright, diseños industriales registrados y activos propios de la actividad comercial como contratos de licencia de uso, concesiones, secretos comerciales, bases de datos y cartera de clientes. Los recursos intangibles, por su parte, que constituyen habilidades o competencias, incluyen la experiencia de los empleados, proveedores y distribuidores y la cultura de la organización (Grant, 1991; Hall, 1992).

Como recursos de capital humano (recursos humanos) se cuenta con las personas que ejercen los distintos cargos de la empresa y sus competencias. Entre otros se encuentran los siguientes: grado de capacitación, experiencia, forma de razonar y tomar decisiones, potencial de aprendizaje, apertura al cambio, capacidad de adaptación, habilidad de trabajo en equipo, relaciones personales, liderazgo, espíritu emprendedor y aspectos sicológicos y sociológicos (Barney, 1991; Grant, 1996).

Entre los recursos de capital organizacional están la estructura organizativa, las líneas de autoridad, la forma de reportes, la planeación formal e informal y el control y la coordinación de sistemas. Por otrolado, se tiene a la cultura organizacional, la cual se relaciona con los valores, tradiciones y normas sociales de la organización y es considerada un recurso intangible clave y una fuente esencial de ventajas competitivas sostenibles. 
La importancia de los recursos se acentúa cuando están integrados de una manera flexible y eficiente para aventajar a la competencia. Por consiguiente, las organizaciones, para alcanzar el éxito, requieren recursos únicos y especiales, que sean difíciles de observar, de imitar y de ser adquiridos.

\subsubsection{Las capacidades de la empresa}

Las capacidades o competencias son un conjunto de conocimientos, habilidades y tecnologías que surgen del aprendizaje colectivo de la organización. Esto como consecuencia de la combinación de recursos y de la creación de rutinas organizativas que se desarrollan por intercambio de información, en particular, con base en el capital humano de la empresa. Estas dependen del sistema de incentivos e integración del personal (Cuervo, 1993).

Las competencias resultan de la interacción entre una tecnología, un aprendizaje colectivo y los procesos organizacionales. Estas permiten crear nuevos recursos para la empresa. Aunque no son un sustituto de los recursos, ellas facilitan y permiten su acumulación. Se trata, en conjunto, de conocimientos y aptitudes colectivas y originales de la empresa (Sterne, 1992).
A corto plazo, la competitividad de una empresa deriva de los atributos precio/funcionamiento de sus productos. Alargo plazo, en cambio, esta depende de la habilidad de crear competencias más rápidamente y a menor precio que los competidores. Así, el verdadero origen de la ventaja competitiva para una compañía se encuentra en la habilidad de los administradores para consolidar la tecnología o aumentar la calidad de los productos y servicios en relación con los ofrecidos por los competidores (Barney 1991).

Las competencias, a diferencia de lo que ocurre con los bienes físicos que se deterioran con el tiempo, no disminuyen con el uso. Estas se acrecientan cuando se aplican y representan, de algún modo, la acumulación del capital intelectual de la empresa.

\subsection{Enfoque basado en los recursos y capacidades}

Grant (1991) afirma que mientras los recursos son el origen de las capacidades de una empresa, estas son la principal fuente de su ventaja competitiva. Recursos y capacidades están entonces relacionados, pues no sería posible acumular las capacidades necesarias para poner en práctica la estrategia competitiva si se 
dificulta el acceso a los recursos (Dierickx \& Cool, 1989). La relación entre estos dos aspectos de la compañía se puede apreciar en la figura 1.

Figura 1. Relación entre recursos y capacidades

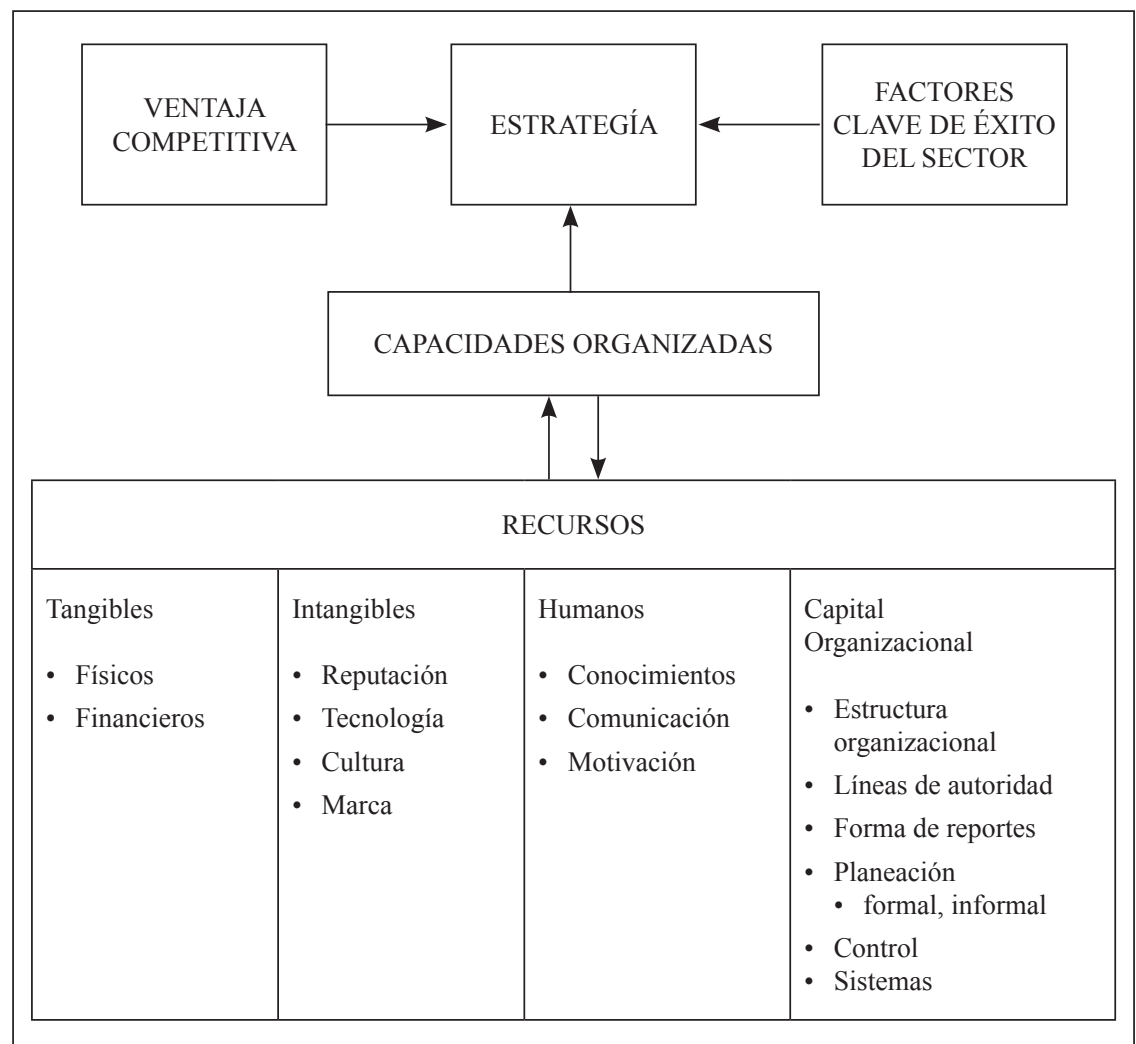

Fuente: Grant (1996, pp. 189).

Suárez e Ibarra (2004), sostienen que mientras que la visión convencional de obtención de ventaja competitiva se orienta hacia sus fuentes genéricas, que son la ventaja en costos, la diferenciación y el enfoque (Porter, 1982), la perspectiva basada en los recursos y capacidades justamente sitúa a estos como la principal fuen- te de la ventaja competitiva de las organizaciones.

Grant (1991) planteó un esquema consistente en cinco etapas para formular el enfoque de obtención de ventaja competitiva basado en la teoría de los recursos y capacidades. Este se muestra en la figura 2. 
Figura 2. Enfoque basado en la teoría de los recursos y capacidades

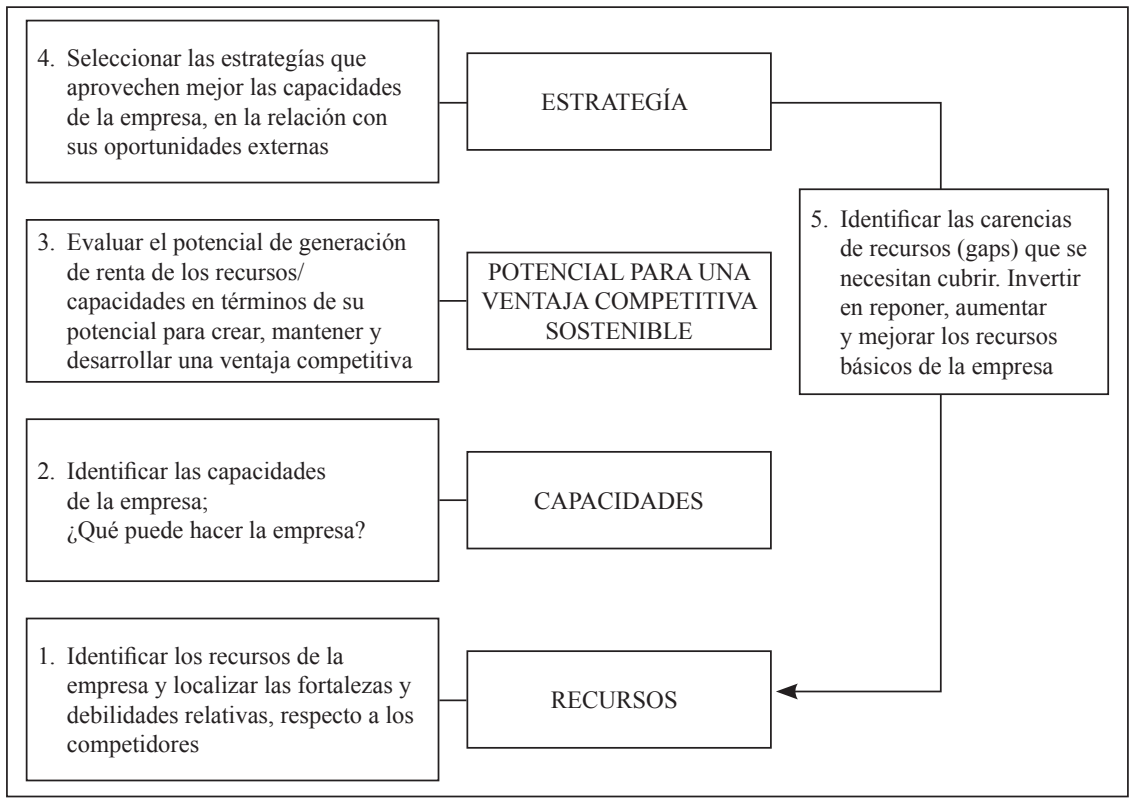

Fuente: Grant (1991, pp. 194).

El enfoque basado en los recursos y capacidades para la obtención de ventaja competitiva, enfatiza el hecho de que en una misma industria existe heterogeneidad entre las empresas. Las diferencias entre estas se crean y persisten precisamente debido a los recursos propios que cada una de ellas utiliza y, en particular, a la manera en que los aprovecha (Díaz, 2003).

Uno de los objetivos centrales de este enfoque es comprender por qué las empresas difieren dentro de un mismo medio ambiente. Se busca identificar también las fuerzas de inercia que mantienen estas diferencias, considerando que estas fuerzas son la base de los distintos niveles de desempeño de las compañías (Barney, 1986).

Este enfoque destaca la importancia de considerar los recursos específicos con los que cuenta una empresa en la concepción de su estrategia, pues estos le permiten a la empresa ser verdaderamente única. Establece que, según la naturaleza de sus recursos, la compañía tendrá una posición competitiva mejor o peor, de acuerdo con la forma en que los sepa utilizar y aprovechar. 


\section{METODOLOGÍA}

\subsection{Proceso de investigación}

La investigación se realizó en dos etapas, a saber: 1) establecimiento de la estrategia metodológica y 2) ejecución del trabajo empírico. En la primera, se realizó la revisión de la literatura para delimitar el contexto del problema y desarrollar el marco teórico; después se planteó la situación problemática, los objetivos e hipótesis de investigación, para continuar con la especificación y operacionalización de las variables y la definición del tipo y enfoque de la investigación. A continuación, en el diseño de la investigación, se definió la población y muestra, las unidades de observación y análisis, se elaboró el instrumento de medición y se realizó el pretest así como las pruebas de validez y confiabilidad del mismo.

En la segunda etapa, se organizó el trabajo de campo y se procedió a la aplicación del instrumento para la recopilación de los datos. Estos se procesaron para proceder al análisis, el desarrollo de conclusiones y la presentación global del proceso realizado y de los resultados. El proceso de este trabajo atendió al rigor de la investigación científica, adoptándolo de acuerdo con los requerimientos del objeto de estudio y considerando el alcance y las limitaciones del estudio (Rojas, 1999). El método seguido para la investigación que aquí se presenta se describe a continuación (Molina, 2005):

1. Se concibe la idea con base en la investigación de la industria textil y del vestido en México. Se consultan diversos informes de instituciones y organismos públicos $y$ de otras entidades relevantes para la investigación. Se revisa también la literatura acerca de los factores que inciden en la competitividad empresarial y su relación con los recursos y capacidades de la empresa.

2. Una vez concebida la idea, se plantea el problema de investigación, presentándolo en forma de pregunta. Se muestra la relación entre las variables dependiente (competitividad) e independientes (productividad, calidad e innovación).

3. Se establece el objetivo, el cual, por medio de los resultados de la investigación, pretende aportar un modelode competitividadpara la industria textil y del vestido.

4. Se realiza la especificación y operacionalización de las variables de investigación, estableciendo dimensiones e indicadores correspondientes.

5. Se establece la definición del tipo $\mathrm{y}$ enfoque de la investigación y 
a continuación, en el diseño, se define la población y muestra, las unidades de observación, las unidades de análisis y se elabora el instrumento de medición.

6. Se organiza el trabajo de campo y se realiza la aplicación del instrumento elegido para la recopilación de los datos.

7. Los datos obtenidos se procesan para su análisis, conclusiones y resultados.

8. Se elabora el reporte final de la investigación.

La metodología sigue un enfoque cuantitativo. Utiliza la recopilación y análisis de datos para contestar las preguntas de investigación, probar las hipótesis establecidas y establecer patrones de comportamiento de la población (Hernández, Fernández $\&$ Baptista, 2008). Se fundamenta en un esquema hipotético-deductivo.

Se consideran para el estudio las habilidades de razonamiento deductivo y el pensamiento hipotético. Este se identifica como el último periodo de la secuencia del desarrollo cognitivo que surge de una combinación de la maduración y la experiencia (Piaget, 1997). Así, se parte de hipótesis científicas formuladas que se confirman o no luego, una vez se realizan sucesivas pruebas contrastadas y positivas.
El alcance de la investigación es aplicada y tecnológica (Bunge, 2009). El objeto del conocimiento es la competitividad y su unidad de análisis es la industria textil y del vestido en México. El paradigma de investigación adoptado es el positivista (Kuhn, 2007). Este señalaque elconocimiento se puede configurar a partir de cuatro supuestos interrelacionados, a saber: 1) la teoría ha de ser universal, 2) los enunciados científicos son independientes de los fines y los valores de los individuos, 3) el mundo social existe como un sistema de variables y 4) las medidas han de ser fiables.

\subsection{Variables de investigación}

Considerando lo indicado antes, la variable 'competitividad' contempla tres dimensiones: crecimiento, rentabilidad y valor de la empresa. La variable 'productividad' comprende seis: activos físicos, activos intelectuales, activos comerciales, recursos humanos (capacidades del personal), recursos organizacionales (capacidades de la organización) y cultura organizacional. La variable 'calidad' considera seis: activos físicos, activos intelectuales, recursos humanos (capacidades del personal), recursos organizacionales (capacidades de la organización), cultura organizacional y reputación. La variable de 'innovación' agrupa seis: transferencia 
tecnológica, investigación y desarrollo (I+D), activos intelectuales, recursos humanos (capacidades del personal), recursos organizacionales (capacidades de la organización) y cultura organizacional.

\subsection{Tipo y enfoque de la investigación}

Esta investigación, en cuanto a su finalidad, es aplicada (Bunge, 2009). En cuanto a su alcance, es correlacional y describe las relaciones entre la variable dependiente (competitividad) y las variables independientes (productividad, calidad e innovación) (Méndez, 2006; Sierra, 2008). El estudio es de corte transversal, atendiendo a su dimensión temporal, ya que se realiza en un único lapso de tiempo (Méndez, 2006; Sierra, 2008). La aplicación del instrumento de investigación se realizó durante dos meses, una vez concluido el trabajo de campo. Los datos recopilados se procesaron para proceder luego a su análisis, conclusiones y a la presentación de los resultados.

El enfoque de la investigación, por su parte, es de tipo cuantitativo. En este se recopilan datos para procesarlos y probar hipótesis con base en la medición numérica y el análisis estadístico (Hernández, Fernández, \& Baptista, 2008).
Dentro de la tipología de investigaciones en las ciencias sociales, atendiendo al alcance de la investigación, se utilizó la clasificación de Bunge (1990). Esto hace que la presente corresponda a una investigación por finalidad, específicamente tecnológica. En esta se desarrolla un modelo de competitividad a nivel empresa e industria (CEPAL, 2003; Chesnais, 2001; Cho, 1994 Esser, Hillebrand, Messner, \& Meyer Stamer, 1994; Feenstra, 1998; OCDE, 2000; Porter, 1991; Sallenave, 1995; Tamames, 1988; Vallejo, 2003).

El tipo de diseño de este trabajo es no experimental (Kelinger \& Lee, 2008). Su objetivo es determinar si existe una relación positiva y directa entre las variables independientes: 1) productividad, 2) calidad y 3) innovación, en relación con la variable dependiente: competitividad. No se pretende la manipulación de variables. Se observan situaciones ya existentes, tal y como se dan en su contexto natural, y no provocadas por el investigador (Hernández, Fernández, \& Baptista, 2008).

\subsection{Unidades de observación y análisis}

En esta investigación se establecen como unidades de observación, las empresas de la industria textil y del vestido en México. Las unidades de 
análisis corresponden a la competitividad de las empresas de la industria textil y del vestido y los factores que inciden en ella (productividad, calidad e innovación).

\subsection{Población y muestra}

De acuerdo a datos proporcionados por el Instituto Nacional de Estadística y Geografía (INEGI, 2014), en su encuesta anual de la industria manufacturera, en 2012, el número de empresas de la industria textil era de 249 , mientras que las compañías de la industria de la confección sumaban 910 en el mismo año, obteniéndose una población total de 1159 organizaciones.

El tamaño de la muestra se obtiene de acuerdo a la fórmula para poblaciones finitas (Münch, 1990), comparando valores estándar de nivel de confianza alto del $95 \%$ con error de estimación del $5 \%$, contra nivel de confianza del $90 \%$ con error de estimación de $110 \%$, eligiendo el máximo posible en términos de recursos disponibles.

Se considera adecuado elegir el tamaño de muestra de nivel de confianza del $90 \%$ con error de estimación del $10 \%$, ya que se desea un nivel alto de confianza y se estima que es posible manejar ese tamaño de muestra con los recursos disponibles. Por esta razón, el tamaño de muestra elegido es de 64 empresas.

\subsection{Tipo de muestreo}

El tipo de muestreo utilizado es estratificado, por tamaño de empresa, de acuerdo al número de empleados usando cuatro estratos: micro, pequeña, mediana y gran empresa. El conjunto de todos los estratos representa a las empresas de la industria textil (dedicada a la producción de insumos, fibras sintéticas o naturales) y de la confección (enfocada a la fabricación de todo tipo de productos textiles, incluyendo prendas de vestir) en México. Para cada estrato se obtiene una muestra independiente que lo representa.

\subsection{Estratificación de la muestra}

Se emplean los datos de estratificación de las unidades económicas de las industrias manufactureras de los Censos Económicos 2009 (INEGI, 2011) correspondientes al porcentaje de empresas por estrato. Estos se multiplican por el valor de la muestra de investigación, que fue calculado utilizando los datos de la encuesta anual de la industria manufacturera de 2012 (INEGI, 2014). Se realiza también una asignación proporcional al tamaño de los estratos, esto es, acorde al número de empresas de 
la industria textil y de la confección que existían en cada uno de estos en 2012.

\subsection{Elaboración del instrumento de investigación}

El instrumento de la investigación para la recopilación de datos consiste en un cuestionario estructurado. Se emplean ítems de nivel ordinal y una escala de evaluación tipo Likert. Una vez definido el cuestionario, previo a su aplicación a la totalidad de la muestra determinada para la investigación, se realizó el pretest. Esto con el fin de hacer un análisis cuantitativo y cualitativo de las preguntas y respuestas que lo componen y determinar así la capacidad de discriminación de las preguntas, evaluar la claridad del contenido y determinar el tiempo promedio requerido para su aplicación. Tras su revisión y evaluación se realizaron ajustes de redacción y estructura en el cuestionario para resolver puntos relacionados con una eventual dificultad para su aplicación, al realizar las preguntas, así como con posibles problemas de compresión o dificultades para responder por parte del entrevistado. El instrumento final quedó conformado por 118 ítems, los cuales fueron agrupados en 21 dimensiones. Cada ítem tiene un valor máximo de 5 puntos y un valor mínimo de 1 punto.

\subsection{Validez y confiabilidad del instrumento}

De acuerdo con Kerlinger y Lee (2008), la validez de un instrumento de medición es la propiedad definida como la exactitud con la que es posible realizar mediciones significativas y adecuadas con el mismo, es decir, que el instrumento realmente permita medir el rasgo para el cual fue creado. Por su parte, Thorndike (1989) sostiene que la validación del instrumento responde a las cuestiones de a qué hacen referencia los puntajes obtenidos, si es válido el uso o la interpretación de las puntuaciones del test, así como qué generalizaciones se pueden realizar apropiadamente a partir de la puntuación de la prueba.

La American Psychological Association (APA) establece que la validez puede ser de tres tipos: de contenido, de constructo y de criterio o predictiva, siendo la segunda la principal entre estas (Messick, 1995). La validez de contenido pone mayor énfasis en la construcción de los reactivos o ítems, la de criterio lo hace en la utilidad práctica (predictiva) del instrumento de medida y la de constructo otorga mayor importancia a su poder explicativo, es decir, al grado en el que un test mide el constructo que pretende medir. 
La confiabilidad de un instrumento se refiere al grado de exactitud con que este permite medir aquello para lo cual fue concebido. Con el propósito de determinar el coeficiente de confiabilidad del instrumento de investigación (valores de 0 a 1) fueron utilizados los dos siguientes métodos estándar de medición de fiabilidad: Método del coeficiente alfa de Cronbach (valor $=0,994)$ y Método de las dos mitades - Split Half(valor=0,997).

Para determinar si los datos recopilados poseen una distribución de tipo normal(normalizada)y poderasí emplear análisis paramétrico para su estudio, se realizaron las pruebas de normalidad de Kolmogorov-Smirnov (con la aplicación de la corrección introducida por Lilliefors) y de Shapiro-Wilk. En la tabla 4 se pueden observar los resultados de las dos pruebas. Las hipótesis estadísticas son:

- $\mathrm{H}_{0}$ : Los datos siguen una distribución normal

- $\mathrm{H}_{1}$ : Los datos no siguen una distribución normal

Tabla 4. Pruebas de normalidad

\begin{tabular}{|c|c|c|c|c|c|c|}
\hline \multicolumn{7}{|c|}{ Pruebas de normalidad } \\
\hline & \multicolumn{3}{|c|}{ Kolmogorov-Smirnov ${ }^{a}$} & \multicolumn{3}{|c|}{ Shapiro-Wilk } \\
\hline & Estadístico & gl & Sig. & Estadístico & gl & Sig. \\
\hline Productividad & ,227 & 64 &, 000 &, 814 & 64 &, 000 \\
\hline Calidad & ,219 & 64 &, 000 & 819 & 64 &, 000 \\
\hline Innovación & ,200 & 64 &, 000 &, 800 & 64 &, 000 \\
\hline Competitividad & ,210 & 64 & 000 & ,814 & 64 &, 000 \\
\hline
\end{tabular}

a. Correción de la significación de Lilliefors

Fuente: elaboración propia, a partir de los datos del cuestionario (programa IBM-SPSS ${ }^{\circledR} 19.0$ ).

Aplicando la interpretación de p-valor (prueba unilateral), dado que se cumple la condición establecida de que el valor del estadístico de la prueba es superior a 0,05 , tanto para la prueba de normalidad de Kolmogorov-Smirnov, como para la de Shapiro-Wilk, se considera que no hay elementos para rechazar la hipótesis $\mathrm{H}_{0}$ y se concluye que los valores de las cuatro variables de investigación, a saber: competitividad, productividad, calidad e innovación, se ajustan a una distribución de tipo normal. Por esta razón, pueden ser aplicadas pruebas paramétricas para su análisis. 


\section{RESULTADOS}

\subsection{Análisis descriptivo}

En lo concerniente a los resultados obtenidos por medio del análisis descriptivo de los datos se determinaron los estadísticos media, mediana, moda, varianza y desviación típica o desviación estándar para cada una de las variables de la investigación (competitividad, productividad, calidad e innovación) y se determinó el nivel correspondiente a cada una de ellas. Esto respecto al valor máximo o mínimo esperado dentro del rango de valores, de acuerdo con los intervalos de las categorías definidas. Se clasificó luego el nivel de la media calculada para la variable en 1) muy alta, 2) alta, 3) regular, 4) baja y 5) muy baja.

Se obtuvo que el valor de la media para todas las variables se encuentra dentro del nivel de la escala denominado '4) baja', ubicándose muy cerca del valor del límite inferior del intervalo. Para cada una de las variables del estudio, la desviación estándar abarca poco más de la longitud de un intervalo, por lo que la mayoría de los entrevistados ubican a sus empresas en niveles de competitividad, productividad, calidad e innovación que van desde el límite inferior del intervalo denominado 'muy baja' $(66,24 \%$ al $64,84 \%$ de los encuestados) hasta el límite inferior del intervalo denominado 'media' (6,34\% al $8,92 \%$ de los encuestados).

\subsection{Análisis de correlación}

La correlación entre dos variables se refiere al grado de parecido o variación conjunta existente entre las mismas. Una relación lineal positiva entre dos variables significa que sus valores varían de forma parecida, mientas que una relación lineal negativa entre las mismas significa que los valores de las variables varían de forma inversa.

\subsubsection{Coeficiente de correlación}

La correlación de Pearson (r) es la medida de la relación lineal entre dos variables. Los valores del coeficiente de correlación van de 1 a -1. El signo indica la dirección de la relación y su valor absoluto indica la fuerza de la relación. Los valores mayores señalan que la relación es más estrecha. Del análisis de correlación para las variables (competitividad, productividad, calidad e innovación) se obtuvieron los resultados acerca del grado de correlación que existe de forma bilateral entre las mismas. Este se muestra en la tabla 5. 
Tabla 5. Correlación entre variables

\begin{tabular}{|c|c|c|c|c|c|}
\hline \multicolumn{6}{|c|}{ Correlaciones } \\
\hline & & Productividad & Calidad & Innovación & Competitividad \\
\hline \multirow{5}{*}{ Productividad } & Correlación de Pearson & 1 & ,991 & ,990 & ,989 \\
\hline & Sig. (bilateral) & &, 000 &, 000 &, 000 \\
\hline & $\begin{array}{l}\text { Suma de cuadrados y } \\
\text { productos cruzados }\end{array}$ & 76989,938 & 65296,094 & 62610,156 & 21325,344 \\
\hline & Covarianza & 1222,063 & 1036,446 & 993,812 & 338,498 \\
\hline & $\mathrm{N}$ & 64 & 64 & 64 & 64 \\
\hline \multirow{5}{*}{ Calidad } & Correlación de Pearson & ,991 & 1 & ,989 & ,983 \\
\hline & Sig. (bilateral) &, 000 & &, 000 &, 000 \\
\hline & $\begin{array}{l}\text { Suma de cuadrados y } \\
\text { productos cruzados }\end{array}$ & 65296,094 & 56400,859 & 53522,266 & 18148,984 \\
\hline & Covarianza & 1036,446 & 895,252 & 849,560 & 288,079 \\
\hline & $\mathrm{N}$ & 64 & 64 & 64 & 64 \\
\hline \multirow{5}{*}{ Innovación } & Correlación de Pearson & ,990 & ,989 & 1 & ,984 \\
\hline & Sig. (bilateral) &, 000 &, 000 & &, 000 \\
\hline & $\begin{array}{l}\text { Suma de cuadrados y } \\
\text { productos cruzados }\end{array}$ & 62610,156 & 53522,266 & 51923,609 & 17431,141 \\
\hline & Covarianza & 993,812 & 849,560 & 824,184 & 276,685 \\
\hline & $\mathrm{N}$ & 64 & 64 & 64 & 64 \\
\hline \multirow{5}{*}{ Competitividad } & Correlación de Pearson & ,989 & ,983 & ,984 & 1 \\
\hline & Sig. (bilateral) &, 000 &, 000 &, 000 & \\
\hline & $\begin{array}{l}\text { Suma de cuadrados y } \\
\text { productos cruzados }\end{array}$ & 21325,344 & 18148,984 & 17431,141 & 6044,109 \\
\hline & Covarianza & 338,498 & 288,079 & 276,685 & 95,938 \\
\hline & $\mathrm{N}$ & 64 & 64 & 64 & 64 \\
\hline
\end{tabular}

** La correlación es significativa al nivel 0,01 (bilateral).

Fuente: elaboración propia, a partir de los datos del cuestionario (programa IBM-SPSS ${ }^{\circledR} 19.0$ ). 


\subsubsection{Coeficiente de determinación}

Al elevar al cuadrado el coeficiente de correlación se obtiene el coeficiente de determinación $\left(\mathrm{r}^{2}\right)$ el cual indica la proporción de variabili- dad conjunta de las variables. Los coeficientes de correlación y determinación de las variables (competitividad, productividad, calidad e innovación) pueden observarse en la tabla 6 .

Tabla 6. Coeficientes de correlación y determinación

\begin{tabular}{|l|c|c|c|c|c|c|c|c|}
\cline { 2 - 9 } \multicolumn{1}{c|}{} & \multicolumn{2}{c|}{ Productividad } & \multicolumn{2}{c|}{ Calidad } & \multicolumn{2}{c|}{ Innovación } & \multicolumn{2}{c|}{ Competitividad } \\
\hline Variable & $(\mathrm{r})$ & $(\mathrm{r}) 2$ & $(\mathrm{r})$ & $(\mathrm{r}) 2$ & $(\mathrm{r})$ & $(\mathrm{r}) 2$ & $(\mathrm{r})$ & $(\mathrm{r}) 2$ \\
\hline Productividad & 1 & 1 & 0,9909 & 0,9819 & 0,9903 & 0,9806 & 0,9886 & 0,9773 \\
\hline Calidad & 0,9909 & 0,9819 & 1 & 1 & 0,9890 & 0,9782 & 0,9830 & 0,9662 \\
\hline Innovación & 0,9903 & 0,9806 & 0,9890 & 0,9782 & 1 & 1 & 0,9840 & 0,9682 \\
\hline Competitividad & 0,9886 & 0,9773 & 0,9830 & 0,9662 & 0,9840 & 0,9682 & 1 & 1 \\
\hline
\end{tabular}

El coeficiente de determinación ( $\mathrm{r} 2$ ) se obtiene al elevar al cuadrado el coeficiente de correlación (r)

Fuente: elaboración propia, a partir de los datos del cuestionario (programa IBM-SPSS ${ }^{\circledR}$ 19.0).

Los resultados muestran que entre la variable independiente (competitividad) y cada una de las variables independientes (productividad, calidad e innovación) existe una relación lineal positiva y estrecha. Esto indica un alto grado de variación conjunta entre cada par de variables, así: competitividad y productividad, competitividad y calidad y competitividad e innovación. El análisis de correlación muestra un valor alto, cercano a 1, tanto para el coeficiente de correlación (r) como para el de determinación $\left(\mathrm{r}^{2}\right)$.

Estos resultados permiten confirmar lo que diversos autores, identificados antes en la revisión de la literatura, señalan acerca de que la competitividad, en cualquiera de sus tres niveles (empresa, industria y país), puede obtenerse principalmente a través del enfoque en tres factores clave (productividad, calidad e innovación) y que estos deben ser aplicados a los recursos y a las capacidades (habilidades) de la empresa.

Finalmente, el análisis de correlación efectuado revela que entre las variables independientes (productividad, calidad e innovación) existe también una relación lineal positiva y fuerte. Esto indica un alto grado de variación conjunta entre cada par de 
variables, a saber: productividad y calidad, productividad e innovación y calidad e innovación. El análisis de correlación muestra un valor cercano a 1, tanto para el coeficiente de correlación (r) como para el coeficiente de determinación $\left(\mathrm{r}^{2}\right)$.

\subsection{Modelo de competitividad}

El objetivo de esta investigación fue determinar en qué medida los factores de productividad, calidad e innovación, enfocados a los recursos y capacidades de la empresa, inciden en su competitividad. Esto con el fin de contar con los elementos necesarios para diseñar un modelo de competitividad para el desarrollo de estrategias que generen ventajas competitivas a las empresas de la industria textil y del vestido en México.

La revisión de la literatura sobre estrategia competitiva y competitividad, teniendo presente la situación actual de la industria textil y del vestido en México y la evolución reciente de sus indicadores clave de desempeño, permitió obtener una serie de elementos que fueron empleados para establecer la estrategia metodológica y el diseño de la investigación. Se planteó de este modo la situación problemática, los objetivos, las preguntas, las hipótesis y la justificación de la investigación, la especificación y operacionalización de las variables, el método de investigación y el diseño del instrumento.

Se realizó el análisis descriptivo de los datos y la determinación de sus estadísticos de tendencia central y de dispersión, así como el análisis de correlación y determinación de las variables de investigación. Se efectuó además el contraste de hipótesis, obteniendo que este arrojaba evidencia suficiente para aceptar las hipótesis de trabajo, a saber: existe un alto grado de correlación entre la variable dependiente (competitividad) y las variables independientes (productividad, calidad e innovación). Además, se encontró que entre las variablesindependientes: (productividad, calidad e innovación) existe igualmente una relación lineal positiva y fuerte, lo que indica un alto grado de variación conjunta entre estas.

A partir de estos elementos y atendiendo al objetivo general de esta investigación, se presenta a continuación el diseño de un modelo de competitividad basado en los factores de productividad, calidad e innovación, enfocados a los recursos y capacidades de la empresa para el desarrollo de estrategias que generen ventajas competitivas a las empresas de la industria textil y del vestido en México (ver figura 3). 
Figura 3. Modelo de competitividad

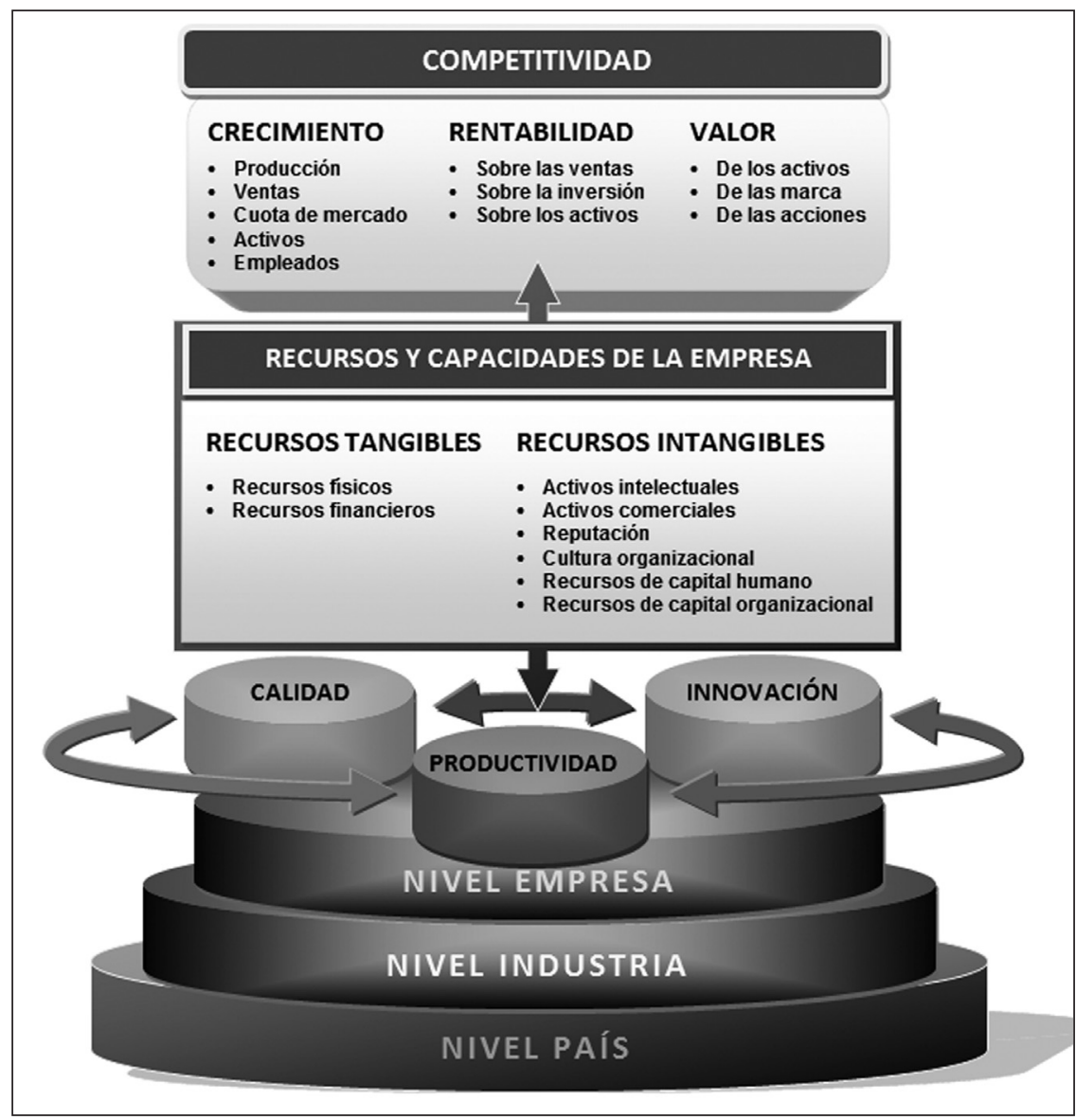

Fuente: elaboración propia, a partir del trabajo realizado y considerando principalmente las obras de Abd-el-Rahman (1995), Alonso (1992), Barney (1991), Barney y Arikan (2001), Barney y Griffin (1992), Cardona (2011), CEPAL (2003), Chesnais (1986; 2001), Cho (1994), Coriat (1997), CPCI (1991), Díaz (2003), Esser, Hillebrand, Messner y Meyer-Stamer, (1994), Fagerberg (1998), Fajnzylber (1988), Feenstra (1998), Galbraith (2005), Grant (1991; 1996), Guerrero (1995), Hall (1992), Müller (1995), OCDE (2000), Pérez (1996), Porter (1982; 1989; 1991), Sallenave (1995), Tamames (1988), Tavares, Haguenauer y Bosco (1990), Tyson (1992), Vallejo (2003), WEF (2013), Wernerfelt (1984), Weston y Brigham (1994).

En el modelo se indican los tres niveles de competitividad (empresa, industria y país). La competitividad, en cualquiera de estos, puede obtenerse principalmente a través del en- foque en tres factores clave: productividad, calidad e innovación. Estos deben ser aplicados a los recursos y las capacidades (habilidades) de la empresa. 
La relación lineal positiva y fuerte, que indica un alto grado de variación conjunta entre cada par de variables (productividad y calidad, productividad e innovación y calidad e innovación) se representa a través de las flechas que existen entre ellas. El incremento de la competitividad, a su vez, se ve reflejado en el crecimiento, mayor rentabilidad y aumento del valor de la empresa. Finalmente, debido a la relación lineal positiva existente entre la variable dependiente y las variables independientes, el incremento de la competitividad incide en el mejoramiento de la productividad, calidad e innovación en las empresas.

\section{CONCLUSIONES}

Los resultados obtenidos en esta investigación aportan evidencia empírica acerca de que los factores de productividad, calidad e innovación, aplicados a los recursos y capacidades de la empresa, tienen una relación directa con la competitividad empresarial y, en particular, con la de las empresas de la industria textil y del vestido en México. Esto confirma lo hallado por otras investigaciones que han sido debidamente identificadas en este trabajo.

El análisis descriptivo de las variables de investigación determinó niveles bajos. Estos son consistentes con los valores y la tendencia a la baja mostrada en los últimos años por los principales indicadores económicos de la industria textil y de la confección mexicana.

El análisis de correlación mostró que existe una relación lineal positiva y muy elevada entre las variables. Esto implica que el mejoramiento de los factores de productividad, calidad e innovación incide de forma directa y positiva en la competitividad de las empresas de la industria textil y del vestido en México.

Con respecto a la hipótesis de investigación, los valores de los coeficientes de correlación y determinación obtenidos para cada par de variables arrojan evidencia suficiente para aceptar la hipótesis de investigación: productividad, calidad e innovación, tienen una relación positiva y directa con la competitividad de las empresas de la industria textil y del vestido en México. En relación con las hipótesis de trabajo se obtuvo evidencia suficiente para aceptar las que fueron planteadas. Por otra parte, se encontró que también existe una fuerte correlación entre las tres variables independientes, a saber: productividad y calidad, productividad e innovación y calidad e innovación. Como resultado, se identifica que el mejoramiento de cualquiera de estas impacta de forma positiva en las otras dos. 
Con los resultados obtenidos, se realizó el diseño de un modelo de competitividad para el desarrollo de estrategias que generen ventajas competitivas para las empresas de la industria textil y del vestido en México. Esto basado en la relación que existe entre los factores de productividad, calidad e innovación, enfocados a los recursos y capacidades de la empresa.

Así, se cumplieron de manera satisfactoria tanto el objetivo general como los específicos de esta investigación, puesto que se logró establecer en qué medida cada una de las variables independientes propuestas (productividad, calidad einnovación) inciden en la variable dependiente (competitividad), de las empresas de la industria textil y del vestido en México.

\section{REFERENCIAS}

Abd-el-Rahman,K.(1995).Uneéconomiemondiale. Specialisation et competitivité. Le Commerce International (Cahiers Français), 253, 20-24.

Alic, J. A. (1987). Evaluating industrial competitiveness at the office of technology assessment. Technology in Society, 9(1), 1-17.

Alonso, J. (1992). Ventajas comerciales y competitividad: aspectos conceptuales y empíricos. Infor- mación Comercial Española (ICE), 705, 38-76.

Barney, J. (1986). Strategic factor markets: Expectations, luck and business strategy. Management Science, 32(10), 1231-1241.

Barney, J. (1991). Firm resources and sustained competitive advantage. Journal of Management, 17(1), 99-120.

Barney, J. (1991). Special theory forum. The resource-based model of the firm: Origins, implications, and prospects. Journal of Management, 17(1), 97-98.

Barney, J. B., \&Arikan, A. M. (2001). Theresource-based view: Origins and implications. En M. A. Hitt, R. E. Freeman \& J. S. Harrison (Eds.), The blackwell handbook of strategic management (pp. 124188). Oxford, UK - Malden, MA: Blackwell.

Barney, J. B., \& Griffin, R. (1992). The management of organizations: Strategy, structure, behavior. Boston: Houghton Mifflin Co.

Bunge, M. (1990). La ciencia. Su método y su filosofía. México: Grupo Patria Cultural.

Bunge, M. (2009). Estrategías de la investigación científica. Perú: Universidad Inca Garcilaso de la Vega.

Burns, T., \& Stalker, G. M. (1961). The management of innovation. London: Tavistock Publications. 
Cardona, R. (2011). Estrategia basada en los recursos y capacidades. Criterios de evaluación y el proceso de desarrollo. Revista electrónica Forum Doctoral, 4, 113-147.

Chesnais, F. (1986). Science, technologie et compétitivité. STI Review, 1, 85-129.

Chesnais, F. (Ed.) (2001). La mundialización financiera. Génesis, costo y desafios. Buenos Aires: Editorial Losada.

Cho D., \& Moon, H. (2002). Evolution of competitiveness theory. London: World Scientific.

Comisión Económica para América Latina y el Caribe (CEPAL) (2003). Informe económico anual. Santiago de Chile: CEPAL.

Comisión Presidencial para la Competitividad Industrial (CPCI) (1991). Competitividad: Un proyecto nacional. (Decretos $N^{\circ} 294$ $y N^{\circ} 312$. Caracas, juniode 1989). Informe final de la Comisión Presidencial para la Competitividad Industrial, Octubre de 1991. Caracas: CPCI.

Coriat, B. (1997). Los desafios de la competitividad. Buenos Aires: Eudeba.

Cuervo, A. (1993). El papel de la empresa en la competitividad. Papeles de Economía Española, 56, 363-377.

David, F. R. (2011). Strategic management: Concepts and cases (13th ed.). Upper Saddle River: Prentice Hall.

Díaz, I. (2003). Marketing y competitividad: ¿Relación o contradicción? Economía y Desarrollo, 132(1), 112-119.

Dierickx, I., \& Cool, K. (1989). Asset stock accumulation and sustainability of competititve advantage. Management Journal, 35(12), 1504-1511.

Esser, K., Hillebrand, W., Messner, D., \& Meyer Stamer, J. (1994). Competitividad sistémica: competitividad internacional de las empresas y politicas requeridas. Berlín: Instituto Alemán de Desarrollo.

Fagerberg, J. (1988). International Competitiveness. Economic Journal, 98(391), 355-374.

Fajnzylber, F. (1988). Competitividad internacional: evolución y lecciones. Revista de la CEPAL, 36, 7-24.

Feenstra, R. C. (1998). Integration of trade and disintegration of production in the global economy. Journal of Economic Perspectives, 12(4), 31-50.

Francis, A., \& Tharakan, P. K. (Eds.) (1989). The competitiveness of European industry. Londres Nueva York: Routledge.

Galbraith, J. K. (2005). Which resources matter the most to firm success? An exploratory study of resourced-based theory. Technovation, 25(9), 979-987. 
Grant, R. M. (1991). The resourcebased theory of competitive advantage: Implications for strategy formulation. California Management Review, 33(3), 114-135.

Grant, R. M.(1996). Dirección estratégica: Conceptos, técnicasyaplicaciones (5aed). Madrid: Civitas.

Guerrero, D. (1995). Competitividad: Teoría y política. Barcelona: Ariel.

Hall, R. (1992). The strategic analysis of intangible resources. Strategic Management Journal, 13(2), 135-144.

Harrison, M. I. (1987). Diagnosing organizations: Methods, models, and processes. Newbury Park: SAGE.

Hernández, R., Fernández, C., \& Baptista, L. (2008). Metodología de la investigación. México: Mc-Graw Hill.

Instituto Mexicano para la Competitividad (IMCO) (2010). Índice de competitividad urbana 2010 del IMCO. Acciones urgentes para las ciudades del futuro. México: IMCO.

Instituto Nacional de Estadística y Geografía (INEGI) (2011). Censos económicos (2009). Micro, pequeña, mediana y gran empresa: estratificación de los establecimientos: censos económicos 2009. México: INEGI.

Instituto Nacional de Estadística y Geografía (INEGI) (2014).
Encuesta Anual de la Industria Manufacturera: EAIM 2012: SCIAN 2007. México: INEGI. International Institute for Management Development (IMD). (2013). IMD world competitiveness yearbook. Ginebra: IMD.

Kerlinger, F., \& Lee, H. (2008). Investigación del comportamiento: Métodos de investigación en ciencias sociales ( $4^{\mathrm{a}}$ ed.). México: Mc-Graw Hill Interamericana.

Kuhn, T. S. (2007). La estructura de las revoluciones cientificas. México: Fondo de Cultura Económica.

Méndez, C. (2006). Metodología, diseño y desarrollo del proceso de investigación con énfasis en ciencias empresariales. Bogotá: Limusa Noriega Editores.

Messick, S. (1995). Standards of validity and the validity of standards in performance assessment. Educationalmeasurement:Issues and Practice, 14(4), 5-8.

Michalet, C.A. (1981). Competitividad e internacionalización. París: OCDE.

Molina, R. (2005). Estrategias administrativas para la difusión de las acciones de Gobierno en el Estado de Hidalgo. México: Instituto Politécnico Nacional.

Moon, H. C., Rugman, A. M. y Verbeke, A. (1995). The generalized double diamond approach to international competitiveness. En 
A. M. Rugman, J.v. d. Broec \&A. Verbeke (eds.), Beyond the diamond (Research in Global Strategic Management, Volume 5) (pp. 97-114). Bingley: Emerald. Morales, M., \& Pech, J. (2003). Competitividady estrategia: el enfoque de las competencias esenciales y el enfoque basado en los recursos. Contaduría y Administración, 197, 47-63.

Müller, G. (1995). El caleidoscopio de la competitividad. Revista de la CEPAL, 56, 137-148.

Münch, L., \& Ángeles, E. (1990). Métodos y técnicas de la investigación (2a ed.). Barcelona: Editorial Trillas.

Organización Mundial del Comercio (OMC) (2013). Organización Mundial del Comercio. Estadisticas del Comercio Internacional 2013. Ginebra: OMC.

Organización para la Cooperación y el Desarrollo Económicos (OCDE) (2000). Informe Anual 2000. París: OCDE.

Pérez, C. (1996). La modernización industrial en América Latina y la herencia de la sustitución de importaciones. Comercio Exterior, 46(5), 347-363.

Piaget, J. (1997). Estudios de psicología genética. Argentina: Emecé Editores.

Porter, M. (1982). Estrategia competitiva. México: CECSA.
Porter, M. (1989). Ventaja competitiva. México: CECSA.

Porter, M. (1990). ¿Dónde radica la ventaja competitiva de las naciones? Harvard-Deusto Business Review, 44(1), 3-26.

Porter, M. (1991). La ventaja competitiva de las naciones. Barcelona: Plaza \& Janes Editores.

Rialp, A. (2003). Fundamentos teóricos de la organización de empresas. Madrid: Pirámide.

Rojas, R. (1999). Guía para realizar investigacionessociales. México: Plaza y Valdez.

Sallenave, J. P. (1995). La gerencia integral. Bogotá: Grupo Editorial Norma.

Secretaría de Economía (2014a). Industria textil. México: Secretaría de Economía. Recuperado el 31 de enero de 2014, de http:// www.economia.gob.mx/files/ comunidad_negocios/industria comercio/informacionSectorial/ sector textil.pdf

Secretaría de Economía (2014b). Industria de la confección. México: Secretaría de Economía. Recuperado el 31 de enero de 2014, de http://www.economia.gob.mx/ files/comunidad negocios/industria comercio/informacionSectorial/confeccion_170114.pdf

Sierra, R. (2008). Técnicas de investigación social. Teoría y ejercicios. Madrid: Thompson. 
Sterne, D. (1992). Core competencies: The key to corporate advantage. Multinational Business, 3, 13-20.

Stoner, J., Freeman, R., \& Gilbert, D. (1996). Administración. México: Pearson Prentice Hall.

Suárez, J., \& Ibarra, S. (2004). La teoría de los recursos y capacidades. Un enfoque actual en la estrategia empresarial. Anales de Estudios Económicos y Empresariales, 15, 63-89.

Tamames, R., \& Gallego, S. (1988). Diccionario de economía y finanzas. Madrid: Alianza Editorial.

Tavares, J., Haguenauer, L., \& Bosco, J. (1990). Proteção, competividade e desempenho exportador da economia brasileira nos anos 80 [Reestructuración Industrial y Competitividad Internacional (24-27dejuliode 1989:CEPAL)]. Pensamiento Iberoamericano: Revista de Economía Politica, 17, 13-38.
Thorndike, R. L. (1989). Psicometría aplicada. Mexico: Limusa.

Tyson, L. (1992). Who's bashing whom? Tradeconflictinhightechnology industries. Washington: Institute for International Economics.

Vallejo, P. (2003). Competencia y estrategia empresarial. Bogotá: Editorial Pontificia Universidad Javeriana.

Wernerfelt, B. (1984). A resourcebased view of the firm. Strategic Management Journal, 5(2), 171-180.

Weston, J., \& Brigham, E. (1994). Fundamentos de administración financiera. México: Mc-Graw Hill.

World Economic Forum (WEF) (1996). Informe de competitividad mundial. Oxford: Oxford University Press.

World Economic Forum (WEF) (2013). The global competitiveness report 2012-2013. Génova: WEF. 